\title{
Comparison of successive discrimination reversal (SDR) performances of seven mammalian species on a spatial task'
}

\author{
ROBERT L. GOSSETTE, GAYLE KRAUS, AND JEFFREY \\ SPEISS, COMPARATIVE ANIMAL BEHAVIOR LABORATORY, \\ HOFSTRA UNIVERSITY, Hempstead, N, Y. 11550
}

The successive discrimination performances of four species of Procyonidae, one species of Mustelidae, and two species of Cebidae were compared. Capuchin monkey and Cacomistle differed significantly from each other and from the remaining species.

It is increasingly evident that mammals, birds (Gossette, 1966), and probably the higher reptiles (Bitterman, 1965) will display improvement or error reduction across a series of successive discrimination reversal (SDR) problems. Similarly it is becoming apparent that unlike simple conditioning and discrimination measures (Warren, 1965) SDR measures do yield significant inter-species performance differences among birds (Gossette, Gossette, \& Riddell, 1966) and among New World monkeys (Gossette \& Inman, 1966) consistent with taxonomic ranking. While SDR measures appear to provide clear separation among remotely related species within a Class, as taxonomic distance decreases the behavioral separation is frequently lost. However, little attention has been given to SDR analysis among closely related species.

The present study provides comparisons of SDR performance of four species of Procyonidae, one species of Mustelidae, with both new and previously reported data for Squirrel and Capuchin monkeys.

Subjects

Procyonidae was represented by four Coati-mundis (Nasua nasua), three Kinkajous (Potos flavus), four Cacomistles (Bassariscus astutus), and four Raccoons (Procyon lotor). Mustelidae was represented by four Striped Skunks (Mephitis mephitis). An additional four Squirrel monkeys were included to increase the sample size of this group beyond that previously reported. All Ss had been received from local animal importers and had been maintained in the laboratory for 6 to 12 months prior to experimentation. While the exact ages of all Ss was impossible to determine exactly, size upon receipt suggested that they were at least $1 \frac{1}{2}$ to 2 years old at the start of testing. All Ss were maintained on diets typical of those employed in local zoos. The characteristic nocturnal habits of the Kinkajous and Cacomistles were gradually replaced by a diurnal pattern by controlling feeding times.

\section{Apparatus}

Testing of all Ss took place in a formboard box, previously described (Gossette \& Inman, 1966). A spatial habit, requiring the displacement of the correct stimulus block to obtain a recessed food reward, constituted the basic problem to be learned.

Procedure

All Ss first received about one month's habituation to confinement within the test chamber. During this time they were adapted to food deprivation, and permitted to eat a small amount of food, later to serve as a reward, from the stimulus platform. Each $S$ was fed once a day, with the testing period occurring during the last hour before feeding. Thus, each $\mathrm{S}$ was maintained on a $23 \mathrm{~h}$ deprivation schedule. A small piece of grape was employed as reinforcer for the Squirrel monkey, Skunk, Kinkajou, Coati-mundi and Raccoon. A small piece of Prime was the reinforcer for the

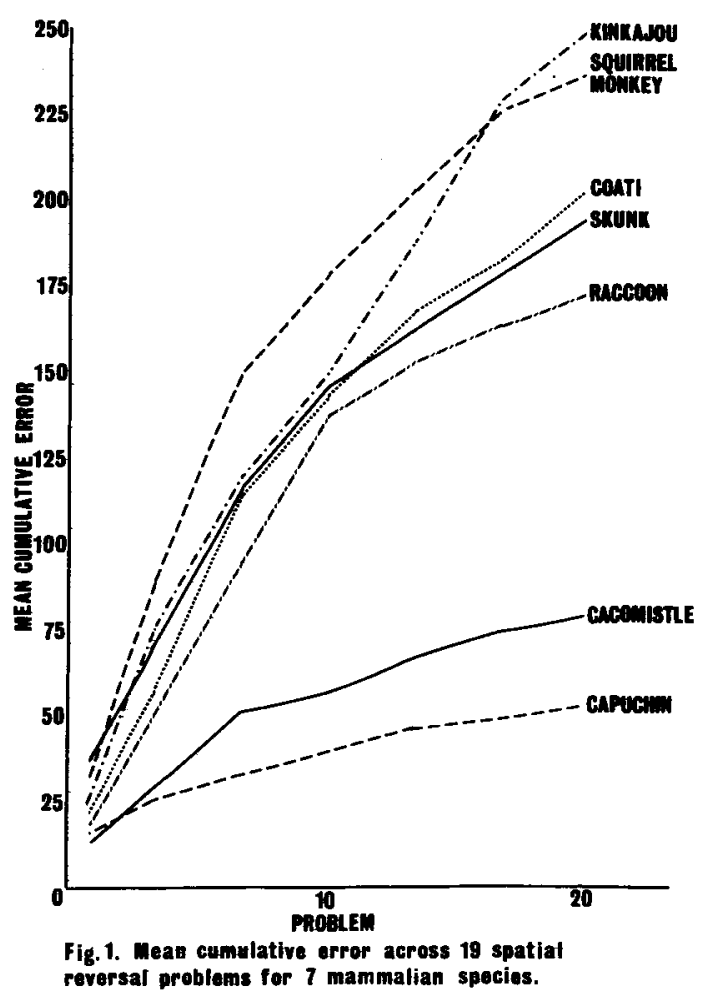

Fig. 1. Mean cumulative error across 19 spatial reversal problems for seven mammalian species.

Cacomistle. Each $\mathrm{S}$ was trained to retrieve food from the foodwell, first when it was uncovered, and then when it was covered with a block. Next, with food under only one of the covered foodwells, position preference was recorded during a 20 -trial session. On the next day spatial discrimination training was initiated. Response to the nonpreferred side was reinforced. Daily sessions of 20 trials each were given until a criterion of 18 correct responses during a given session had been attained. The following day reinforcement contingencies were reversed and training proceeded as before. A total of 19 reversals were obtained.

Results and Discussion

The principal response measure chosen for analysis was the total number of errors across 20 problems. Figure 1 shows the cumulative error curves for all groups. The curve for the Capuchin was obtained from an earlier study. The Squirrel monkey curve includes data previously reported plus that obtained from four new Ss in this study. Table 1 provides the ranges and mean errors for each group. A test of mean cumulative errors across all species by Kruskal-Wallis indicated significant inter-species differences $(\mathrm{p}<.01)$. However, more specific comparisons indicated that the major contribution to this difference was the superiority of the Cacomistles and the Capuchins. There were no significant differences among the Squirrel monkeys, Raccoons, Coatis, Kinkajous,

Table 1

Range and Mean Error for Seven Mammalian Species Across 19 Reversals of a Spatial Habit

\begin{tabular}{lccccccc} 
& Capuchin & Squirrel monkey & Cacomistle & Coati-mundi & Kinkajou & Raccoon & Skunk \\
\hline Mean & 54.2 & 223.0 & 83.5 & 203.8 & 253.7 & 174.0 & 193.8 \\
Range & $43-75$ & $150-289$ & $74-92$ & $144-280$ & $237-265$ & $99-244$ & $136-283$ \\
\hline
\end{tabular}

Psychon. Sci., 1968, Vol. 12 (5) 
or Skunks. The Capuchins, however, were significantly $(\mathrm{p}<.05)$ superior to the Cacomistles. Analysis of errors across problems revealed essentially the same pattern. One interesting feature emerged though; both the Capuchins and Cacomistles failed to show an increase in errors on the first or subsequent reversals as exhibited by the remaining groups, and most mammals and birds tested on this task. Instead, they displayed a progressive reduction of errors from Problem 1, the original habit, to the final problem.

The present data provides additional confirmation that SDR measures can differentiate between Capuchin and Squirrel monkeys. However, the failure generally to find such a separation among the Carniveres indicates that a more sensitive task and/or methodology must be employed to isolate such differences-if they exist. The clear superiority of the Cacomistles over the remaining Carniveres is puzzling. An interesting hypothesis, advanced by Rensch (1963), that among closely related species, the species with the smaller body mass, but the relatively larger brain, will show superior "learning ability," could account for this anomaly. Among the Procyonidae, the Cacomistle is typically the smallest, with the Raccoon and Coati, the largest. A similar pattern of differences has been found among the Phasianidae (Gossette, 1968).

One promising approach to increasing the sensitivity of SDR methodology to inter-species differences may be through increasing task difficulty. Previous work with birds (Gossette, 1967), has shown that while performances of closely related species were quite similar on a spatial SDR, they differed prominantly on a brightness SDR.

\section{REFERENCES}

BITTERMAN, M. E. The evolution of intelligence. Scient. American, 1965, 212, 92-100.

GOSSETTE, R. L. Successive discrimination reversal (SDR) performances of four avian species on a brightness task. Psychon. Sci., 1967, 8, I.

GOSSETTE, R. L. Successive discrimination reversal measures and interspecies taxonomic distance. Submitted for publication, 1968.

GOSSETTE, R. L., GOSSETTE, M., \& RIDDELL, W. Comparisons of successive discrimination reversal performances among closely and remotely related species. Anim. Behav., 1966, 14, 560-564.

GOSSETTE, R. L., \& INMAN, N. Comparison of spatial successive discrimination reversal performances of two groups of New World monkeys. Percep. mot. Skills, 1966, 23, 169-170.

RENSCH, B. The relation between the evolution of the central nervous functions and the body size of animals. In J. Huxley, A. C. Hardy, and E. Ford, (Eds.), Evolution as a process. New York: Collier Books, 1963.

WARREN, J. M. Comparative psychology of learning. Annu. Rev. Psychol, Vol. 16, 1965.

\section{NOTE}

1. The data reported above was supported in part by Grant No. 14079-01 awarded to the senior author by NIMH. 